\title{
Níveis de treonina digestível em rações para suínos machos castrados de alto potencial genético na fase dos 95 aos $125 \mathrm{~kg}^{1}$
}

\author{
Fabrício de Almeida Santos ${ }^{2}$, Juarez Lopes Donzele ${ }^{3}$, Rita Flávia Miranda de Oliveira ${ }^{3}$ \\ Francisco Carlos de Oliveira Silva ${ }^{4}$, Márvio Lobão Teixeira de Abreu ${ }^{5}$, Alysson Saraiva ${ }^{2}$
}

\author{
1 Financiado pelo CNPq. \\ 2 Doutorando DZO/UFV. \\ ${ }^{3}$ DZO/UFV. \\ ${ }^{4}$ EPAMIG. \\ ${ }^{5}$ DZO/UFPI
}

RESUMO - Este estudo foi realizado para avaliar o efeito dos níveis de treonina digestível na dieta sobre o desempenho e a composição da carcaça de suínos machos castrados de alto potencial genético para deposição de carne. Oitenta suínos com peso inicial de 95,87 \pm 1,26 kg foram distribuídos em delineamento experimental de blocos ao acaso, com cinco níveis de treonina digestível $(0,470 ; 0,497 ; 0,528 ; 0,557$ e $0,587 \%$, correspondentes às relações treonina digestível:lisina digestível de 58,0; 61,0; 65,0; 69,0 e 73,0\%, respectivamente), cada um com oito repetições e dois animais por unidade experimental. As rações experimentais e a água foram fornecidas à vontade até o final do período experimental, quando os animais atingiram $125,26 \pm 2,59 \mathrm{~kg}$. Os níveis de treonina digestível das rações não influenciaram o consumo diário de ração e o ganho de peso dos animais, mas tiveram efeito quadrático sobre a conversão alimentar, que melhorou até o nível estimado de 0,526\% de treonina na ração. O consumo diário de treonina digestível aumentou de forma linear de acordo com os níveis desse aminoácido na ração. Os níveis de treonina digestível da ração não influenciaram o peso de carcaça, a quantidade de carne, a espessura de toucinho no ponto $\mathrm{P}_{2}$ e a deposição diária de carne. O nível de treonina digestível de 0,526\%, correspondente a uma relação de $65 \%$ com a lisina digestível e a um consumo de treonina digestível de 18,49 g/dia, proporciona os melhores resultados de conversão alimentar em suínos machos castrados de alto potencial genético na fase dos 95 aos $125 \mathrm{~kg}$.

Palavras-chave: aminoácidos, carcaça, desempenho, genótipo, nutrição, terminação tardia

\section{Digestible threonine levels in diets for barrows of high genetic potential in the phase from 95 to $125 \mathrm{~kg}$ live weight}

\begin{abstract}
The objective of this study was to evaluate the effect of digestible threonine levels on performance and carcass composition of barrows of high genetic potential for meat deposition. Eighty barrows with initial weight of $95.87 \pm 1.26 \mathrm{~kg}$ were distributed in a randomized block design, with five treatments $(0.470 ; 0.497 ; 0.528 ; 0.557 ; 0.587 \%$, corresponding to digestible threonine:digestible lysine ratio of $58.0 ; 61.0 ; 65.0 ; 69.0$ and $73.0 \%$, respectively) with eight replications and two animals in each experimental unit. The experimental feeds and water were supplied ad libitum until the end of the experimental period, when the animals reached $125.26 \pm 2.59 \mathrm{~kg}$. The digestible threonine levels in the diets did not influence daily feed intake and weight gain, but had a quadratic effect on feed conversion, which improved up to the estimated level of $0.526 \%$ threonine in the diet. The daily digestible threonine intake increased linearly according to the levels of this amino acid in the diet. The digestible threonine levels did not influence carcass weight, lean meat gain, back fat thickness at $\mathrm{P}_{2}$ and daily lean meat deposition. The $0.526 \%$ digestible threonine level, corresponding to a ratio of $65 \%$ digestible lysine and $18.49 \mathrm{~g}$ /day digestible threonine intake, lead to the best feed conversion results for high genetic potential barrows, in the phase from 95 to $125 \mathrm{~kg}$.
\end{abstract}

Key Words: aminoacids, carcass, genotype, late finishing, nutrition, performance

\section{Introdução}

As novas linhagens de suínos comercializadas atualmente apresentam alto potencial de deposição de carne na carcaça, o que possibilita abater animais com peso superior a $95 \mathrm{~kg}$ sem alterar significativamente o desempenho dos animais.

O abate desses animais é mais econômico, pois permite processar carcaças mais pesadas e diluir os custos fixos por unidade de peso em maior quantidade de produto, reduzindo

Recebido em 29/8/2008 e aprovado em 17/3/2009.

Correspondências devem ser enviadas para: donzele@ufv.br 
os custos fixos por animal produzido. Além do maior rendimento de carcaça, o abate de suínos mais pesados resulta em maior rendimento dos cortes, como verificado por Martin et al. (1980), que constataram aumento na área de olho-de-lombo e no comprimento de carcaça de animais abatidos com peso superior a $95 \mathrm{~kg}$.

Uma vez que as novas linhagens apresentam exigências nutricionais diferenciadas, torna-se necessária a atualização dessas exigências para melhorar a eficiência de utilização dos nutrientes e aminoácidos pelos animais. Além disso, o uso de aminoácidos industriais possibilita a redução da poluição ocasionada pela atividade suinícola por meio do ajuste dos nutrientes das rações às exigências dos animais, o que evita o excesso de aminoácidos circulantes no sangue, reduzindo a excreção de nitrogênio pelos animais.

Entre os aminoácidos exigidos pelos animais e cujas necessidades devem ser avaliadas, a treonina tem se destacado por ser normalmente o segundo ou terceiro aminoácido limitante para suínos alimentados com dietas à base de milho, farelo de soja e farelo de trigo (De Blas et al., 2000). A treonina apresenta importantes funções no organismo animal: síntese de proteína muscular, síntese de mucinas no sistema gastrintestinal e síntese de imunoglobulinas no sistema imune.

As exigências de treonina aumentam com o crescimento do animal (Baker, 1993; Rademacher et al., 1999), uma vez que, com o avanço do peso e da idade dos animais, os níveis necessários para mantença são maiores que para deposição proteica (Fuller et al., 1989).

Neste contexto, verificou-se a necessidade de avaliar os efeitos dos níveis de treonina digestível em rações sobre o desempenho e as características de carcaça de suínos machos castrados selecionados geneticamente para deposição de carne na carcaça na fase dos 95 aos 125 kg.

\section{Material e Métodos}

O experimento foi realizado na Granja de Suínos da Fazenda Experimental Vale do Piranga, da EPAMIG, localizada no município de Oratórios, Minas Gerais, no período de maio a julho de 2005.

Foram utilizados 80 suínos machos castrados, com peso inicial de 95,87 $\pm 1,26 \mathrm{~kg}$, híbridos comerciais PIC com alto potencial genético para deposição de carne na fase dos 95 aos $125 \mathrm{~kg}$, distribuídos em delineamento experimental de blocos ao acaso, com cinco tratamentos, cada um com oito repetições de dois animais constituindo a unidade experimental. Na distribuição dos animais dentro de cada bloco, adotou-se como critério o peso inicial.
As rações experimentais (Tabela 1) foram formuladas à base de milho e farelo de soja e suplementadas com minerais e vitaminas, de acordo com as exigências preconizadas por Rostagno et al. (2000). Os tratamentos consistiram dos níveis 0,$470 ; 0,497 ; 0,528 ; 0,557$ e $0,587 \%$ de treonina digestível, correspondentes às relações 58,0; 62,0; 65,0; 69,0 e 73,0\% de treonina digestível:lisina digestível, respectivamente, obtidas a partir de uma ração basal suplementada com L-treonina. Na ração basal, verificou-se a relação aminoacídica entre a lisina e os demais aminoácidos essenciais, a fim de assegurar que em todas as rações nenhum outro aminoácido além da treonina ficasse limitante. Na avaliação das relações aminoacídicas das rações, foram utilizadas as relações preconizadas por Fuller (1996), segundo o conceito de proteína ideal, para suínos de 50 a 110 kg. A L-treonina foi incorporada às rações em substituição ao ácido glutâmico, proporcionalmente às concentrações de nitrogênio, e seu total foi ajustado para 100 kg de ração por meio do acréscimo de amido.

Os animais foram alojados em baias providas de comedouro semi-automático e bebedouros tipo chupeta, localizadas em galpão de alvenaria com piso de concreto e coberto com telha de amianto. As temperaturas do ar foram monitoradas diariamente por meio de termômetro de máxima e mínima.

Durante o período experimental, os animais receberam as rações experimentais e água à vontade. As sobras de ração e os animais foram pesados semanalmente para determinação do ganho de peso, do consumo de ração e da conversão alimentar.

No final do período experimental, quando atingiram o peso final de $125,26 \mathrm{~kg}$ os animais foram mantidos em jejum por 18 horas e, em seguida, foram pesados e encaminhados para o abate, realizado no Frigorífico Industrial do Vale do Piranga (Frivap). Os animais foram insensibilizados por choque elétrico e sacrificados por sangramento. As carcaças foram depiladas com lança-chamas, evisceradas e pesadas e, posteriormente, foram avaliadas quanto à espessura de toucinho e à quantidade de carne, por meio de aparelho de tipificação de carcaça com pistola Henessay Grading Probe (HGP-4), segundo procedimentos adotados no frigorífico.

A deposição diária de carne (DDC) foi estimada utilizando-se os dados de peso inicial dos animais (PI), rendimento de carcaça (RC), peso de carcaça estimado (PCE), porcentagem de carne na carcaça (PC), quantidade de carne final (QCF), quantidade de carne inicial estimada (QCIE) e dias no período experimental (D).

Os valores de rendimento de carcaça e porcentagem de carne na carcaça foram obtidos a partir dos dados de 
Tabela 1 - Composição centesimal das rações experimentais

\begin{tabular}{|c|c|c|c|c|c|}
\hline \multirow[b]{2}{*}{ Ingrediente } & \multicolumn{5}{|c|}{ Nível de treonina digestível (\%) } \\
\hline & 0,470 & 0,497 & 0,528 & 0,557 & 0,587 \\
\hline Milho & 79,820 & 79,820 & 79,820 & 79,820 & 79,820 \\
\hline Farelo de soja & 15,750 & 15,750 & 15,750 & 15,750 & 15,750 \\
\hline Óleo de soja & 0,670 & 0,670 & 0,670 & 0,670 & 0,670 \\
\hline Fosfato bicálcico & 1,223 & 1,223 & 1,223 & 1,223 & 1,223 \\
\hline Calcário & 0,710 & 0,710 & 0,710 & 0,710 & 0,710 \\
\hline Ácido glutâmico & 0,300 & 0,265 & 0,228 & 0,190 & 0,152 \\
\hline Amido & 0,533 & 0,540 & 0,546 & 0,554 & 0,562 \\
\hline L-lisina $\mathrm{HCl}(78,5 \%)$ & 0,258 & 0,258 & 0,258 & 0,258 & 0,258 \\
\hline DL-metionina (99\%) & 0,065 & 0,065 & 0,065 & 0,065 & 0,065 \\
\hline L-treonina $(98,5 \%)$ & 0,000 & 0,028 & 0,059 & 0,089 & 0,119 \\
\hline L-triptofano (99\%) & 0,023 & 0,023 & 0,023 & 0,023 & 0,023 \\
\hline Premix vitamínico ${ }^{1}$ & 0,150 & 0,150 & 0,150 & 0,150 & 0,150 \\
\hline Premix mineral ${ }^{2}$ & 0,150 & 0,150 & 0,150 & 0,150 & 0,150 \\
\hline Sal comum & 0,318 & 0,318 & 0,318 & 0,318 & 0,318 \\
\hline Bacitracina de zinco & 0,020 & 0,020 & 0,020 & 0,020 & 0,020 \\
\hline $\mathrm{BHT}^{3}$ & 0,010 & 0,010 & 0,010 & 0,010 & 0,010 \\
\hline \multicolumn{6}{|c|}{ Composição nutricional calculada ${ }^{4} /$ estimada $^{5}$} \\
\hline Energia digestível (kcal/kg) & 3.260 & 3.260 & 3.260 & 3.260 & 3.260 \\
\hline Proteína bruta (\%) & 14,23 & 14,23 & 14,23 & 14,23 & 14,23 \\
\hline Lisina total (\%) & $0,840 / 0,904$ & $0,840 / 0,904$ & $0,840 / 0,904$ & $0,840 / 0,904$ & $0,840 / 0,904$ \\
\hline Lisina digestível (\%) & $0,750 / 0,807$ & $0,750 / 0,807$ & $0,750 / 0,807$ & $0,750 / 0,807$ & $0,750 / 0,807$ \\
\hline Treonina digestível (\%) & $0,450 / 0,470$ & $0,480 / 0,497$ & $0,510 / 0,528$ & $0,540 / 0,557$ & $0,570 / 0,587$ \\
\hline Metionina+cistina digestível (\%) & $0,502 / 0,555$ & $0,502 / 0,555$ & $0,502 / 0,555$ & $0,502 / 0,555$ & $0,502 / 0,555$ \\
\hline Triptofano digestível (\%) ${ }^{4}$ & 0,158 & 0,158 & 0,158 & 0,158 & 0,158 \\
\hline Cálcio (\%) & 0,650 & 0,650 & 0,650 & 0,650 & 0,650 \\
\hline Fósforo disponível (\%) & 0,320 & 0,320 & 0,320 & 0,320 & 0,320 \\
\hline Relação Tre:Lis digestível (\%) & 58,0 & 62,0 & 65,0 & 69,0 & 73,0 \\
\hline
\end{tabular}

Rossoni et al. (2008), em que o rendimento de carcaça foi obtido Método Brasileiro de Classificação de Carcaça (MBCC), considerando a relação entre o peso da carcaça quente e o peso vivo final dos animais, enquanto a porcentagem de carne na carcaça foi determinada segundo metodologia utilizada no frigorífico (Frivap).

Abaixo, seguem as equações utilizadas para determinar as variáveis PCE, QCIE, QCE e DDC:

$$
\begin{aligned}
& \mathrm{PCE}=(\mathrm{PI} \times \mathrm{RC}) / 100 ; \\
& \mathrm{QCIE}=(\mathrm{PCE} \times \mathrm{PC}) / 100 ; \\
& \mathrm{QCE}=\mathrm{QCF}-\mathrm{QCIE} ; \\
& \mathrm{DDC}(\mathrm{g} / \mathrm{dia})=(\mathrm{QCE} / \mathrm{D}) \times 1000 ;
\end{aligned}
$$

Avaliaram-se as seguintes variáveis: consumo diário de ração, ganho de peso diário, consumo de treonina digestível, conversão alimentar, espessura de toucinho no ponto $\mathrm{P}_{2}$, quantidade de carne, peso da carcaça $\mathrm{e}$ deposição diária de carne.

As características de desempenho e de carcaça foram analisadas pelo Sistema de Análises Estatísticas e Genéticas (SAEG), desenvolvido pela Universidade Federal de Viçosa (UFV, 2000), versão 8.0, utilizando-se os procedimentos para análises de variância e de regressão, de acordo com o seguinte modelo estatístico:

$$
\mathrm{Y}_{\mathrm{ijk}}=\mu+\mathrm{B}_{\mathrm{i}}+\mathrm{T}_{\mathrm{j}}+\varepsilon_{\mathrm{ijk}}
$$

em que: $\mathrm{Y}_{\mathrm{ijk}}=$ característica observada; $\mu=$ média geral das características; $\mathrm{B}_{\mathrm{i}}=$ efeito do bloco $\mathrm{i} ; \mathrm{i}=1,2 \ldots$ e $8 ; \mathrm{T}_{\mathrm{j}}=$ efeito do nível de treonina $\mathrm{j} ; \mathrm{j}=1,2 \ldots$ e $5 ; \varepsilon_{\mathrm{ijk}}=$ erro aleatório associado a cada observação.

Os níveis de treonina digestível foram obtidos por meio de análises de regressão linear, quadrática e/ou pelo modelo descontínuo Linear Response Plateau (LRP), conforme o melhor ajustamento obtido para cada variável estudada.

\section{Resultados e Discussão}

As temperaturas observadas no termômetro de máxima e mínima foram $25,2 \pm 3,5$ e $17,7 \pm 3,0^{\circ} \mathrm{C}$, respectivamente, durante o período experimental. Considerando que a faixa de termoneutralidade para suínos na fase de terminação é de 12 a $18^{\circ} \mathrm{C}$ (Perdomo, 1994), pode-se inferir que os animais foram expostos a períodos diários de alta temperatura durante o experimento. 
O consumo diário de ração não foi influenciado $(\mathrm{P}>0,05)$ pelos níveis de treonina digestível das rações (Tabela 2). Resultados semelhantes foram obtidos por Johnston et al. (2001) em pesquisa com animais na fase final de terminação (dos 90 aos 120 kg). Do mesmo modo, Pedersen et al. (2003) e Ettle et al. (2004), em experimento com animais dos 70 aos $105 \mathrm{~kg}$ e dos 65 aos $110 \mathrm{~kg}$, respectivamente, também não observaram efeito dos níveis de treonina digestível da ração sobre o consumo diário de ração.

Os resultados de consumo diário de ração obtidos neste estudo não confirmam os relatos de Henry \& Sève (1998) de que suínos selecionados geneticamente para alta taxa de crescimento reduzem a ingestão voluntária de alimento em razão do desequilíbrio de aminoácidos na ração, principalmente de treonina, triptofano e metionina. Estes dados também não estão de acordo com o relato de De Blas et al. (2000) de que o acúmulo de treonina no sangue devido ao seus altos níveis na ração pode prejudicar o consumo de ração em suínos, em virtude da dificuldade desses animais de oxidar o excesso de treonina no plasma.

Apesar de, durante parte do dia, a temperatura máxima $\left(25,2 \pm 3,5^{\circ} \mathrm{C}\right)$ ter excedido a faixa de termoneutralidade para esses animais, o consumo médio diário de ração (3.514,6 g/dia) foi superior ao preconizado por Rostagno et al. (2005) e aos dados obtidos por Johnston et al. (2001), de 2.960 e 3.100 g/dia, respectivamente. Portanto, os períodos diários de altas temperaturas durante o período experimental não foram suficientes para influenciar negativamente o consumo de ração dos animais.

O consumo de treonina digestível aumentou $(\mathrm{P}<0,01)$ de forma linear, segundo a equação: $\hat{Y}=-1,1019+37,2521 X$ $\left(r^{2}=0,98\right)$, à medida que se aumentou a sua concentração na ração. Resultados semelhantes foram observados por Ettle et al. (2004), que também verificaram aumento linear no consumo de treonina digestível de acordo com seu nível na ração.

Como neste estudo o consumo de ração não variou significativamente entre os níveis de treonina digestível, pode-se inferir que o aumento no consumo desse aminoácido esteve diretamente relacionado à sua concentração na ração.
Não se observou efeito dos níveis de treonina digestível $(\mathrm{P}>0,05)$ sobre o ganho de peso diário (GPD). De forma semelhante, Lenis et al. (1990) e Pedersen et al. (2003) também não encontraram variação significativa no ganho de peso diário de suínos na fase de terminação quando aumentaram os níveis de treonina digestível das rações.

Por outro lado, este resultado difere do obtido por Johnston et al. (200), que, em experimento com animais dos 90 aos 120 kg, observaram aumento no ganho de peso diário conforme aumentaram os níveis de treonina digestível. Da mesma forma, Ettle et al. (2004), em estudos com suínos machos e fêmeas dos 65 aos 110 kg, também verificaram aumento no ganho de peso diário dos animais quando aumentaram os níveis de treonina digestível da ração.

Apesar de não ter variado significativamente entre os níveis de treonina digestível, constatou-se aumento gradativo de até 8,18\% no valor absoluto do ganho de peso diário dos animais entre os níveis de 0,470 e 0,528\% de treonina digestível. Esse resultado seria um indicativo de que o nível de $0,528 \%$ de treonina digestível, correspondente a uma relação treonina digestível: lisina digestível de 65\%, estaria mais ajustado à demanda de treonina digestível desses animais para expressarem seu potencial de crescimento.

A variação dos resultados quanto à demanda de treonina para melhor resposta de ganho de peso diário entre os trabalhos pode estar relacionada, entre outros fatores, à genética dos animais quanto à sua capacidade de deposição de carne na carcaça. De acordo com resultado de estudo conduzido por Thong \& Liebert (2004), a demanda de treonina aumentou de 8,96 para 12,22 g/dia quando a capacidade de deposição diária de proteína dos suínos elevou de 130 para $160 \mathrm{~g} /$ dia.

Os níveis de treonina digestível influenciaram $(\mathrm{P}<0,06)$ a conversão alimentar dos animais, que variou de forma quadrática melhorando até o nível estimado de 0,526\% de treonina digestível, correspondente a uma relação de 65\% com a lisina digestível (Figura 1). De forma semelhante, Johnston et al. (2001) e Pedersen et al. (2003), em experimentos com suínos, respectivamente, dos 90 aos 120 kg e dos 70 aos 105 kg, também verificaram influência positiva dos níveis de

Tabela 2 - Consumos diários de ração e de treonina digestível, ganho de peso diário e conversão alimentar de suínos machos castrados dos 95 aos $125 \mathrm{~kg}$ alimentados com rações com diversos níveis de treonina digestível

\begin{tabular}{|c|c|c|c|c|c|c|}
\hline \multirow[t]{2}{*}{ Variável } & \multicolumn{5}{|c|}{ Nível de treonina digestível (\%) } & \multirow{2}{*}{$\begin{array}{l}\text { CV } \\
(\%)\end{array}$} \\
\hline & 0,470 & 0,497 & 0,528 & 0,557 & 0,587 & \\
\hline Consumo diário de ração (g) & 3.507 & 3.494 & 3.453 & 3.602 & 3.517 & 9,42 \\
\hline Ganho de peso diário (g) & 1.112 & 1.156 & 1.204 & 1.159 & 1.116 & 9,97 \\
\hline Conversão alimentar $(\mathrm{g} / \mathrm{g})^{2}$ & 3,16 & 3,02 & 2,88 & 3,12 & 3,15 & 7,02 \\
\hline
\end{tabular}

${ }^{1}$ Efeito linear $(\mathrm{P}<0,01)$.

2 Efeito quadrático $(\mathrm{P}<0,06)$. 
treonina digestível das rações na conversão alimentar dos animais.

A melhora na eficiência de utilização do alimento para ganho de peso neste estudo esteve diretamente relacionada ao aumento não-significativo de $8,18 \%$ na taxa de crescimento diário dos animais, sem a correspondente variação no consumo de ração, até o nível de $0,526 \%$ de treonina digestível. Considerando o nível de 0,526\%, estimou-se em 18,49 g/dia a demanda de treonina digestível para os suínos maximizarem sua eficiência de utilização da ração para ganho de peso.

A exigência de treonina digestível de 18,49 g/dia determinada neste estudo ficou acima dos valores de 11,4, 12,46, e 10,7 g/dia encontrados, respectivamente, por Johnston et al. (2001), Pedersen et al. (2003) e Ettle et al. (2004), com suínos em terminação. Esse valor também foi superior ao de $11.84 \mathrm{~g} /$ dia preconizado por Rostagno et al. (2005) para suínos em fase de terminação tardia (100 aos $120 \mathrm{~kg})$.

A diferença na exigência de treonina digestível em gramas por dia entre os trabalhos pode ser atribuída, entre outros fatores, à genética dos animais e à composição das rações utilizadas nos experimentos. Quanto à genética dos

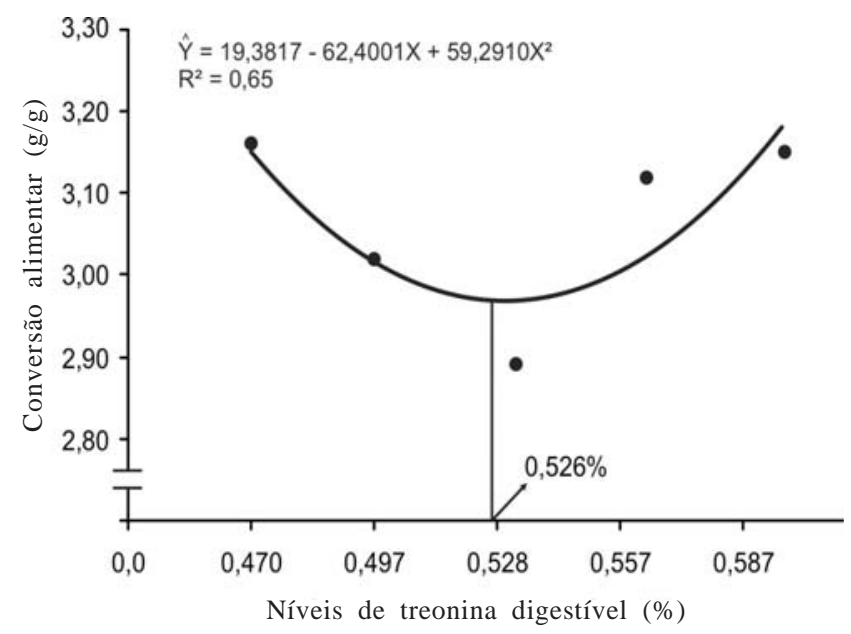

Figura 1 - Conversão alimentar de suínos machos castrados de alto potencial genético dos 95 aos $125 \mathrm{~kg}$ alimentados com rações com diferentes níveis de treonina digestível. animais, em estudos conduzidos com suínos com peso médio de $50 \mathrm{~kg}$, Thong \& Liebert (2004) verificaram que a exigência de treonina variava de acordo com a capacidade de deposição de proteína dos animais, uma vez que aqueles com maior potencial para deposição de carne exigiam maior consumo diário de treonina. Libao-Mercado et al. (2006) constataram que a eficiência de utilização da treonina digestível ingerida para deposição de proteína variava de acordo com os ingredientes utilizados nas rações e, no caso, foi maior quando se utilizou caseína em comparação ao trigo. De forma semelhante, em estudos conduzidos com suínos em crescimento, Beech et al. (1991) verificaram que a eficiência de retenção de treonina digestível altera de acordo com a fonte de proteína utilizada nas rações, tendo variado de $44 \%$ com farelo de algodão até $64 \%$ para o farelo de soja.

Não foi observado efeito $(\mathrm{P}>0,05)$ dos níveis de treonina digestível da ração sobre as características de carcaça avaliadas (Tabela 3). Os dados obtidos estão de acordo com os resultados de Pedersen et al. (2003), que, em estudo com suínos dos 70 aos 105 kg, não observaram efeito do aumento dos níveis de treonina digestível sobre as características de carcaça dos animais quando aumentaram de 58,0 para 70,0\% a relação treonina: lisina digestível. Confirmam também os relatos de Lenis \& Van Diepen (1990), Lenis et al. (1990), Schutte et al. (1997) e Ettle et al. (2004) de que a influência da suplementação de treonina sobre as características de carcaça é menor que sobre o desempenho dos suínos.

No entanto, os resultados obtidos divergem dos encontrados por Johnston et al. (2001), que observaram melhora significativa na porcentagem de carne e na profundidade de lombo (57,4 para 61,2 mm) e redução na espessura de toucinho (19,3 a 17,02 mm) quando aumentaram os níveis de treonina digestível de 0,29 para 0,410\%, correspondente a uma relação de 51 a 73\%, respectivamente, com a lisina digestível.

O fato destes últimos autores terem usado nível inicial de treonina digestível bem abaixo do usado neste estudo, correspondendo a uma relação de $51 \%$ com a lisina, pode ter contribuído para a diferença nos resultados dos trabalhos.

Tabela 3 - Características de carcaças de suínos machos castrados com alto potencial genético alimentados na fase dos 95 aos 125 kg com rações com diversos níveis de treonina digestível

\begin{tabular}{|c|c|c|c|c|c|c|}
\hline \multirow[t]{2}{*}{ Variável } & \multicolumn{5}{|c|}{ Nível de treonina digestível (\%) } & \multirow{2}{*}{$\begin{array}{l}\text { CV } \\
(\%)\end{array}$} \\
\hline & 0,470 & 0,497 & 0,528 & 0,557 & 0,587 & \\
\hline Peso da carcaça (kg) & 87,22 & 87,26 & 85,67 & 88,06 & 87,40 & 3,64 \\
\hline Quantidade de carne (kg) & 50,41 & 49,77 & 49,05 & 50,22 & 49,84 & 4,24 \\
\hline Espessura de toucinho $\mathrm{P}_{2}(\mathrm{~mm})$ & 14,23 & 14,86 & 14,28 & 14,70 & 15,35 & 15,07 \\
\hline Deposição diária de carne (g) & 534,10 & 474,60 & 510,87 & 526,52 & 517,48 & 16,76 \\
\hline
\end{tabular}




\section{Conclusões}

O nível de 0,526\% treonina digestível na ração, correspondente a uma relação de $65 \%$ com a lisina digestível e a um consumo de treonina digestível de 18,49 g/dia, proporciona o melhor resultado de conversão alimentar para suínos machos castrados de alto potencial genético na fase de 95 a $125 \mathrm{~kg}$.

\section{Referências}

BAKER, D.H. Efficiency of amino acid utilization in the pig. In: BIENNIAL CONFERENCE OF THE AUSTRALASIAN PIG SCIENCE ASSOCIATION (APSA), 4., 1993, Canberra. Proceedings... Canberra: APSA, 1993. p.191-197.

BAKER, D.H. Ideal amino acid profiles for swine and poultry and their applications in feed formulation. Biokyowa Technical Review, p.9, 1997.

BEECH, S.A.; BATTERHAN, S.; ELLIOTT, R. Utilization of ileal digestible amino acids by growing pigs: threonine. British Journal of Nutrition, v.65, p.381-390, 1991.

DE BLAS, C.; GARCIA, A.I.; CARABÃNO, R. Necesidades de treonina em animales monogástricos. In: Curso de Especialización - FEDNA, 15., Fira de Barcelona, 2000. Palestras... Fira de Barcelona: 2000. p.1-24.

ETTLE, T.; ROTH-MAIER, D.A.; BARTELT, J. et al. Requirement of true ileal digestible threonine of growing and finishing pigs. Journal Animal.Physiologic Nutrition, v.88, p.211-222, 2004.

FULLER, M.F.; McWILLIAM, R.; WANG, T.C. et al. The optimum dietary amino acid pattern for growing pigs. 2. Requirements for maintenance and for tissue protein accretion. British Journal Nutrition, v.62, p.255-267, 1989.

FULLER, M. Macronutrient requirements of growing swine. In: SIMPÓSIO INTERNACIONAL SOBRE EXIGÊNCIAS NUTRICIONAIS DE AVES E SUÍNOS, 1., 1996, Viçosa, MG. Anais... Viçosa, MG: UFV, Imprensa Universitária, p.205-221, 1996.

HENRY, Y.; SÈVE, B. Feed intake and dietary amino acid balance in growing pigs with special reference to lysine, tryptophan, and threonine. Pig News Production Animal, v.1, p.65-74, 1998.

JOHNSTON, M.E.; BOYD, R.D.; FRALIC, C.E. et al. Optimum threonine:lysine ratio for pigs in the 90 to $120 \mathrm{~kg}$ phase. Journal of Animal Science, v.79, p.42, 2001. (Abstract)

LENIS, N.P.; VAN DIEPEN, J.T.M.; GOEGHART, P.W. Amino acid requirements of pigs.1. Requirement for methionine + cystine, threonine and tryptophan of fast growing boars and gilts, fed ad libitum. Netherlands Journal Agriculture Science, v.38, p.577-595, 1990

LENIS, N.P.; VAN DIEPEN, J.T.M. Amino acid requirements of pigs. 3. Requirements for apparent digestible threonine of pigs in different stages of growth. Netherlands Journal Agriculture Science, v.38, p.609-622, 1990.

LIBAO-MERCADO, A.J.; LEESON, S.; LANGER, S. et al. Efficiency of utilizing ileal digestible lysine and threonine for whole body protein deposition in growing pigs is reduced when dietary casein is replaced by wheat shorts. Journal of Animal Science, v.84, p.1362-1374, 2006.

MARTIN, A.H.; SATHER, A.P.; FREDEEN, H.T. et al. Alternative market weights for swine. II. Carcass composition and meat quality. Journal of Animal Science, v.50, p.699-705, 1980.

PEDERSEN, C.; LINDBERG, J.E.; BOISEN, S. Determination of the optimal dietary threonine:lysine ratio for finishing pigs using three different methods. Livestock Production Science,v.82,233-243. 2003.

PERDOMO, C.C. Conforto ambiental e produtividade de suínos. In: SIMPÓSIO LATINO AMERICANO DE NUTRIÇÃO DE SUÍNOS, 1994, São Paulo, SP. Anais... São Paulo: CBNA, 1994. p.19-26.

RADEMACHER, M.; SAUER, W.C.; JANSMAN, A.J.M. In: (Eds.) Standardized ileal digestible of amino acids in pigs. The new system. Frankfurt: Degussa-Hulls, 1999. 20p.

ROSSONI, M.C.; DONZELE, J.L.; OLIVEIRA, R.F.M. et al. Níveis de treonina digestível para suínos machos castrados de alto potencial genético para deposição de carne na fase de terminação. Arquivo Brasileiro de Medicina Veterinária e Zootecnia, v.60, p.884-889, 2008.

ROSTAGNO, H.S.; ALBINO, L.F.T.; DONZELE, J.L. et al. Composição de alimentos e exigências nutricionais de aves e suínos: tabelas brasileiras. Viçosa, MG: UFV, 2000. 141p.

ROSTAGNO, H.S.; ALBINO, L.F.T.; DONZELE, J.L. et al. Tabelas brasileiras para aves e suínos: composição de alimentos e exigências nutricionais. 2.ed. Viçosa, MG: UFV, Imprensa Universitária, 2005. 186p.

SCHUTTE, J.B.; DE JONG, J.; SMINK, W. et al. Threonine requirement of growing pigs (50 to $90 \mathrm{~kg}$ ) in relation to diet composition. Animal Science, v.64 p.155-161, 1997.

THONG, H.T.; LIEBERT, F. Potential for protein and threonine requirement of modern genotype barrows fed graded levels of protein with threonine as the limiting amino acid. Journal Animal Physiologic Nutrition, v.88, p.196-203, 2004.

UNIVERSIDADE FEDERAL DE VIÇOSA -UFV. SAEG - Sistemas de Análises Estatísticas e Genéticas. Versão 8.0. Viçosa, MG, 2000. 59p. 